\title{
UNIVERSITY OF AZUAY WELLBEING SURVEY 2019
}

ENCUESTA DE BIENESTAR DE LA UNIVERSIDAD DEL AZUAY 2019

Anne Carr ${ }^{1}$

Matias Abad Merchán ${ }^{2}$

Narcisa Ullauri ${ }^{3}$

\begin{abstract}
To embed health into all aspects of campus culture is one of the Calls to Action in the 2015 International Okanagan Charter. The Ministry for Higher Education in Ecuador mandates that an institution maintain a welfare administrative unit to promote the rights of the members of the academic community. Cooperation and communication are central to maintain a campus model of security and wellbeing. This research collected quantitative and qualitative policy-relevant data from students, teachers, and administration representatives to guide institutional change. Recommendations and a suggested plan for action based on the principle finding for increased transparency and directionality of accountability is made.
\end{abstract}

\section{Key Words}

Campus security, cooperation, accountability, wellbeing.

\section{Resumen}

Integrar la salud en todos los aspectos de la cultura del campus es una de las llamadas a la acción en la Carta Internacional de Okanagan de 2015. El Ministerio de Educación Superior de Ecuador exige que una institución mantenga una unidad administrativa de bienestar destinada a promover los derechos de los miembros de la comunidad académica. La cooperación y la comunicación son fundamentales para mantener un modelo de seguridad y bienestar en el campus. Para guiar el cambio institucional, esta investigación recopiló datos relevantes cuantitativos como cualitativos de estudiantes, maestros y representantes de la administración. Las recomendaciones para un plan de acción de cuatro años se basan en el hallazgo principal de una mayor transparencia y direccionalidad de la rendición de cuentas.

\section{Palabras clave}

Seguridad en el campus, cooperación, accountability, bienestar.

\footnotetext{
${ }^{1}$ Universidad del Azuay (Ecuador). Correo electrónico: acarr@uazuay.edu.ec.

${ }^{2}$ Universidad del Azuay (Ecuador). Correo electrónico: matabad@uazuay.edu.ec.

${ }^{3}$ Universidad del Azuay (Ecuador). Correo electrónico: nullauri@uazuay.edu.ec.
} 


\section{Introduction}

The word university is derived from the Latin Universitas magistrorum et scholarium, which means community of teachers and scholars. It is an institution of higher education and research that awards academic degrees in various academic disciplines. In the global knowledge economy higher education is understood as vital to national economic growth and global competition through the preparation of graduates, and the production of research, invention and innovations (Atlbach 2004).

However, various factors including "mission, student population, faculty profile, geographic location, funding sources, level of resources and orientation to local, national and international interests" (Knight 2004, 25) influence why and how a university contextualizes its role.

Stein (2016) suggests that the Latin American model of the university is different from both the Napoleonic enlightenment based elitist professional education and the Humboldtian focused on personal development and academic freedom. Rather the university in the Ecuadorian context and in particular southern Azuay, is inserted into the local community or communities emphasizing collective reflection on the social reality that serves as guidance for the academic (adapted from Morosin in Brackman 2010, 24).

Drawing on Haraway's work on situated knowledges (1988), Puig de la Casa (2016) uses the notion of "thinking with care" to argue how thinking and knowing both necessarily require care in the way they are always already relational processes in a thickly interdependent world. She argues for care and ethics as an analytic, as enacting a speculative, that is, open ended non-predetermined mode of thinking. Thinking with care means asking ourselves, as an institution, if we incorporate only one kind of epistemology when we talk about wellbeing in quantitative terms such as the number of female students sexually assaulted $(2.53 \%)$ on campus or the number of bias motivated violence $(12.1 \%)$ or the number of physically harassed and stalked female students (20.3\%) (University of West Virginia office of strategic planning survey 2016). Quantitative data without accompanying qualitative data can be based in a particular historical, political, socio-economic and cultural circumstances that strongly determine a persistence of a gender supremacy imaginary. For example, according to official Ecuadorian figures, six out of ten women are victims of some kind of violence. Additionally, survey results from a reference group of 3000 Ecuadorian university students found a lack of awareness on the part of men as well as a certain tolerance towards gender violence (Ibanez 2017).

In response to campus gender violence, some universities have taken broad equality and social justice perspective by developing "campus toolkits" to demonstrate a culture of respect by focusing on male students' attitudes (VAWnet 2020) or a mobile app to help students of any gender identify and navigate a range of abuse concerns (Johns Hopkins My Plan 2020).

Internationally, there is a growing body of evidence concerned with the need to address the mental and emotional health and the physical wellbeing of university students (Orygen, 2017). Healthy students are better placed to have a successful student experience while at University (Holt \& Powell, 2017; Baik et al., 2016). In June 2015, participants from 45 countries, representing both educational institutions and health organizations, including the World Health Organization and UNESCO, collaborated on the Okanagan Charter's development: An International Charter for Health Promoting Universities and Colleges.

The Okanagan Charter provides institutions with a common language, principles, and framework to become a "health and wellbeing promoting campus" and outlines two Calls to Action:

- To embed health into all aspects of campus culture, across the administration, operations, and academic mandates;

- To lead health promotion action and collaboration locally and globally

One response to the Okanagan Call to Action: in March 2020, The Women's Health, Gender, and Empowerment Center of Expertise, which is part of the University of California Global Health Institute, sought proposals from global university partners to research to strengthen their campus' prevention and response to sexual assault, harassment, stalking, dating 
violence and other forms of gender-based violence.

\section{Ecuador}

Article 68 of the Higher Education Law in Ecuador (Ley Orgánica de Educación Superior), in what pertains to wellbeing, mandates that Higher Education institutions maintain a welfare administrative unit to promote the rights of the members of the academic community. This department should develop vocational and professional guidance processes and obtain credits, incentives, financial aid, and scholarships. It will offer assistance services that are determined in the regulations of each institution. It will also allocate staff and resources to strengthen this Unit. Among its attributions are:

1. Promoting an environment of respect for the rights and physical, psychological, and sexual integrity of the entire university community;

2. Promoting an environment free of all forms of harassment and violence;

3. Assisting to those who report violations of these rights;

4. Formulating and implementing policies, programs, and projects to prevent and offer immediate care for victims of sexual violence. The student welfare unit, through the legal representative of the higher education institution, will present or initiate the administrative and judicial actions to report any acts of violence that have come to its knowledge;

5. Implementing programs and projects to inform, prevent, and to control the use of drugs, alcoholic beverages, cigarettes, and tobacco products;

6. Coordinating actions with the competent agencies for the treatment and rehabilitation of addictions within the framework of the national drug plan;

7. Generating projects and programs to meet the special educational needs of the population that requires it, as is the case of people with disabilities;

8. Generating projects and programs to promote the integration of historically excluded and discriminated population;

9. Promoting intercultural coexistence;

10. Implementing child care and welfare spaces for the daughters and sons of the institution's students.

\section{Objectives of this research}

In the emergent knowledge society, higher education institutions are positioned to generate, share, and implement knowledge and research findings to enhance citizens' and communities' health and wellbeing both now and in the future. This research's primary objective was to provide policy-relevant data on the extent and distribution of various types of victimization that students, faculty, and staff experience on the University of Azuay campus.

As a way to enter the discourse of wellbeing at UDA and obtain an internal baseline measurement, in January 2019, a campus wellbeing survey was designed to identify information on perceptions concerning the campus' social and cultural climate, responsibility to self-protect and assist others (bystanders). These are bottom-up social accountability concepts that are not externally enforceable but rather at the will of the individual campus members based on their degree of intrinsic motivation.

Additional Survey questions sought perceptions of how UDA would handle a situation in which a student reported sexual misconduct and their knowledge of types of support services that exist. These are externally mandated concepts for which campus members are held accountable. These are top-down social accountability administration driven, for example, university policy on reporting physical or sexual abuse.

A secondary objective was to highlight the distinction between education and prevention. While existing education print posters, webpage administration statements, and online text - may increase awareness and provide the campus community with information about campus policies, procedures, reporting options, and campus resources, it is not sufficient as a stand-alone strategy for reducing violence in particular. Prevention aims to stop the violence before it occurs and reduce the number of incidents on (or off-campus). In addition to the survey, an intervention module to practice specific skills for personal safety, as well as bystander assistance skills in violent incidents, was piloted with a 
convenience sample focus group of students.

Not a component of this research, but an important consideration is how much importance families put on the open discussion of campus safety and what types of programs are offered to students to prevent crime and assist when an incident occurs.

\section{Characteristics of UDA}

The University of Azuay is a private, non-profit institution, co-financed by the Ecuadorian government. It has around 600 teachers and more than 6,000 students.

The University of Azuay began in 1968 and is based in the city of Cuenca, the capital of the province of Azuay. In its beginnings, it was part, first, of the Catholic University Santiago de Guayaquil and, later, of the Pontifical Catholic University of Ecuador. In 1990, after complying with all legal requirements, it was recognized as the University of Azuay through the Law of the Republic.

The University of Azuay offers undergraduate training through its twenty-eight schools distributed in six faculties.

\section{Participants}

Students, faculty, administration, and staff, including janitorial and security, anonymously and voluntarily completed the online survey during February 2019. Only students were invited online and through social media to participate in a photographic competition during March 2019.

\section{Justification for study}

The 2014 Gallup-Purdue Index report, a representative study of 70,000 college graduates in the U.S., found significant evidence to support how six key undergraduate experiences prime graduates to succeed in their work and lives after college. Those experiences include:

1. I had at least one professor at [college] who made me excited about learning.

2. My professor(s) at [college] cared about me as a person.

3. I had a mentor who encouraged me to pursue my goals and dreams.

4. I worked on a project that took a semester or more to complete.

5. I had an internship or job that allowed me to apply what I was learning in the classroom.

6. I was extremely active in extracurricular activities and organizations while I attended [college].

Gallup's research has shown that these college experiences are related to graduates' long-term well-being, encompassing more than just physical health. It measures how individuals feel about and experience their daily lives across five elements: purpose, social, financial, community, and physical health. Overall, the top driver of student well-being is the degree to which a student agrees "they have the opportunity to do what they do best every day" -- one of the key survey questions used to measure student engagement. The second driver was campus safety and security.

No research had previously been undertaken on campus safety and security at the University of Azuay. Coupled with undisclosed rumors of sexual harassment and stalking on campus, the Survey was designed in part as a social justice response to collect policy-relevant data on some types of campus violence and understanding of current institutional responses to wellbeing. The significance of rumors is of psychological, sociological, educational, and economic interest because rumors are information statements in circulation that are unverified. Additionally, rumors are "instrumentally relevant" in that they answer questions that students (and others on campus) want to be answered that they feel are important or significant and because they serve to help understand an ambiguous situation. (Appendix A) 


\section{Photographic competition}

Although quantitative measures such as surveys are paramount in collecting numeric data for large groups, important qualitative data can be collected through visual media, such as photos. Images can prompt a different kind of reflection on lived experiences. As images are able to prompt emotions and thoughts about experiences in ways that narrative alone cannot. This reflection may begin with the making of an image: "why is it that I made that photograph, at that moment?" (Liebenberg 2009).

Such critical reflection can lead to a discussion with others, especially to reach and inform policymakers to bring about change (Harper 1988; Liebenberg et al. 2014). Smith (1987) asserts that it is those who have a voice and participate in decision making that holds power; Wang and Burris argue that "policy is the articulation of voice through the concrete distribution of resources. Whose voices participate in the policy dialogue determines which actions are chosen" (1994:182). For example, Mitchell (2015) demonstrated how participatory visual methods could influence social change and make a significant contribution to policy dialogue.

The collection of both qualitative and quantitative data from community members - students, faculty, and administration - with a view to rethinking approaches to relationality demonstrates in the process that solidarity, participation, and reciprocal partnerships are equally valued. The photographic competition's purpose was to gather reflective products of visually documented social, emotional health, and physical wellbeing. Since both the collection of quantitative and qualitative data was a response to unconfirmed rumors of victimization, particularly of females, it was considered important to model multiple ways of collecting and analyzing data. Additionally, photos and text submitted by students were judged collaboratively by a panel of teachers and student representatives based on the visual and textual messaging of examples of friendship, mobility, solidarity, and respect for each other. After the competition, the photos and text were uploaded to social media.

\section{Intervention module}

The module "Our Voices" was designed by the research team as an immediate intervention response to rumors of physical and/or sexual harassment on campus. The PowerPoint presentation consisted of:

a. Visual and verbal explanation of respect: equality, trust, personal growth, negotiation, communication, role modeling, accountability, and avoiding violence

b. A brief scenario of a physical assault was introduced to inform about types of violence and abuse, issues of power and control followed by:

c. Demonstration of physical and verbal strategies to avoid violence.

d. Students were invited or volunteered to participate in the practice of (c) followed by an informal large group discussion of how these strategies might be applied to the brief scene of a physical assault.

\section{Method}

All university community members (students, teachers, administration, security and building staff) simultaneously were invited to anonymously complete the Survey online through a Google Form received in their institutional email. Besides, to enhance anonymity, respondents were not required to assign gender, age, or academic year on the Survey. The Survey (Appendix A) was available during February 2019. It consisted of 12 items. Eleven of the items were numerically evaluated. The final survey item, "additional comments," was analyzed for thematic content.

The pilot intervention 'Our Voices' as implemented with a convenience group during February 2019. Participants' informal comments were recorded.

During March 2019, students were invited online through institutional email to share their individual or group experiences of friendship, mobility, solidarity, and respect for each other by submitting photos to a competition. Photos were required to be accompanied by a text of not more than 280 characters defining or adding to what could be seen in the photo, what was happening, whether the situation should be discussed, and what could be done about it. A panel 
of four professors from design, international studies, tourism, administration, and a student representative judged the photos on the basis of the effectiveness of the communicative intent of friendship, mobility, solidarity, and respect.

\section{Results}

A total of 718 members of the university community participated in the online Survey. Included in the Administration total are security and building staff.

- Students: 489

- Teachers: 146

- Administration: 83

- Total: 718

There are many similarities, as well as some differences in the quantitative results. For example, all three groups of respondents had high levels of apprehension about personal and property safety outside of the University (Question 1).

Question 2 is related to the perception of the campus's attitude towards the following groups: people with disabilities, foreign students, feminists, gays, lesbians, transgender, indigenous, and Afro-Ecuadorians. Teachers and students rated people with disabilities, foreign students, indigenous and Afro-Ecuadorian similarly high. For administration, the distribution was more even across the groups, perhaps reflecting roles and assignments that are more formal and socially distant compared to teacher and student ongoing experiences.

Question 3 asked respondents if they saw or heard offensive messages either through print, graffiti, or social media. Results are very similar for the three groups, with jokes, comments in general and social media noted as the most likely to occur.

Question 4 required detailed responses concerning respondents' experience of hate scenes, for example, verbal, email, or phone threats, theft of personal property, objects thrown at you, being followed and/or spit on, threatened with physical aggression, calls or sounds, physical assault, unwanted sexual behaviors and/or sexually harassed. Students reported relatively high levels of experience with verbal, web images, property damage, being threatened with calls of sounds as well as sexual harassment. Teachers reported higher levels of verbal and offensive web images as did administration but additionally, property damage.

Question 5 asked for more specific information on whether respondents had been observed or followed by camera or GPS, stalked (on foot), found threatening objects near them, received unwanted social media messages or gifts, been slandered or sent sexual comments social media. Across the three groups, evidence of these experiences was minimal.

Question 6 asked for responses to specific types of harassment, e.g., followed by a camera, received sexually explicit phone/text messages, the pressure to date, and/or unwanted sexual gestures. Students reported the highest levels of unwanted sexual gestures, with all three groups reporting experiences of being followed by a camera.

Question 7: Questions related to intra-familiar physical violence such as pushing, slapping, throwing objects, bent fingers, hair pulling, punching, kicking, burning, threatening, and using a weapon. Students noted low levels across all categories, with teachers and administration noting pushing and object throwing at higher levels than students.

Question 8 sought responses to intervention or bystander strategy use. For example, accompanying a friend who had drunk too much home, asking friends of someone drinking too much to take care of her/him, protesting a sexist joke, asking someone who looked upset if they were OK, distracted someone trying to take advantage of another person who has drunk too much, defending another from physical attack. All groups reported consistently high participation rates across the situations.

Responses related to questions of existing administrative policy, Question 9 (on victim rights and offender sanction), Question 10 (knowing the University protocol for reporting violence), and Question 11 on future policy decisions yielded varying results. 
For example, on question 9: How do you perceive the UDA's actions about inappropriate sexual behaviors? (physical or non-physical contact of a sexual nature in the absence of explicit, conscious, and voluntary consent, for example, sexual or gender-based harassment, harassment, dating violence), administration rated a higher level of satisfaction than teachers and students.

Figure 1. Teachers survey, question 9. How do you perceive the actions of the UDA in relation to inappropriate sexual behaviors? (physical or non-physical contact of a sexual nature in the absence of clear, conscious and voluntary consent, for example, sexual or gender-based harassment, harassment, dating violence).

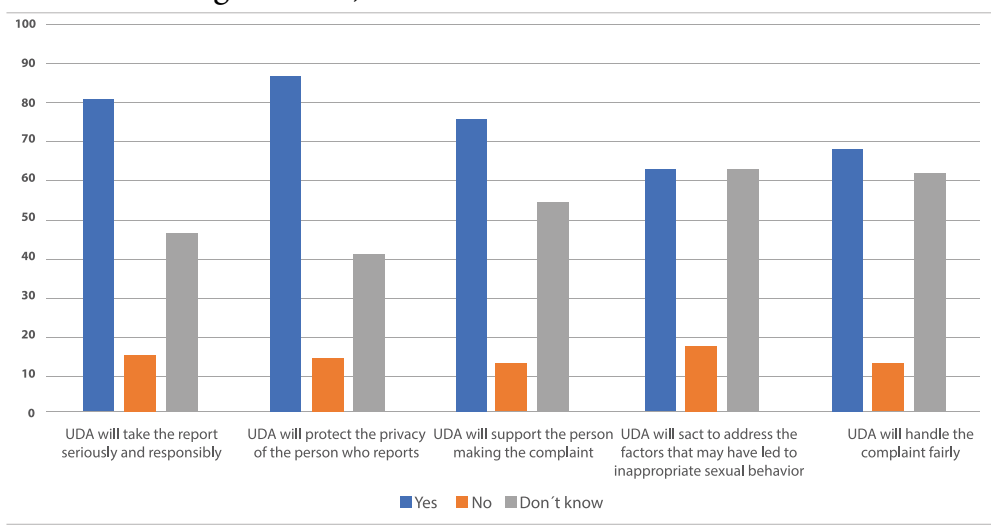

* The scale indicates the number of teachers who answered the survey. Source: Adapted from Gallup Inc. (2014)

Figure 2. Teachers survey, question 9. How do you perceive the actions of the UDA in relation to inappropriate sexual behaviors? (physical or non-physical contact of a sexual nature in the absence of clear, conscious and voluntary consent, for example, sexual or gender-based harassment, harassment, dating violence).

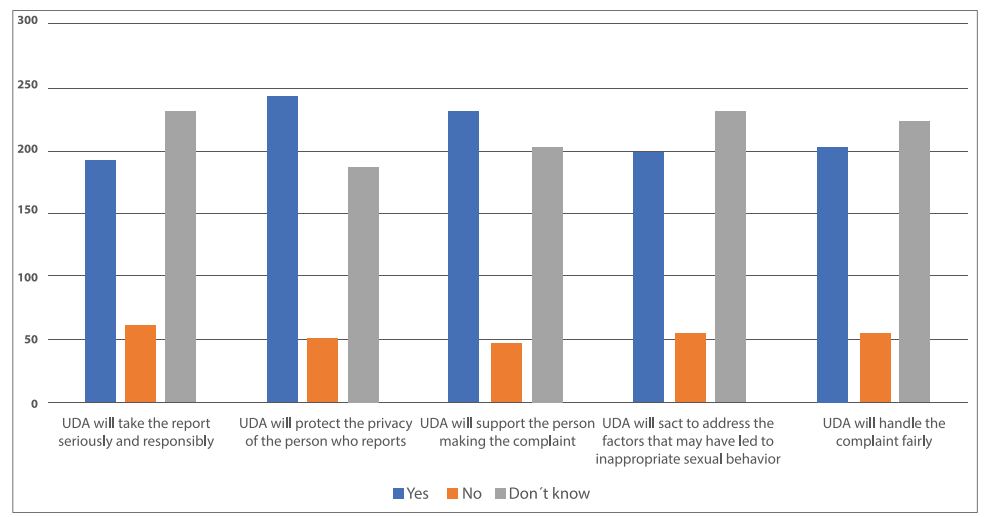

* The scale indicates the number of students who answered the survey. Source: Adapted from Gallup Inc. (2014).

Figure 3. Administrative survey, question 9: How do you perceive the actions of the UDA in relation to inappropriate sexual behaviors? (physical or non-physical contact of a sexual nature in the absence of clear, conscious, and voluntary consent, for example, sexual or gender-based harassment, harassment, dating violence):

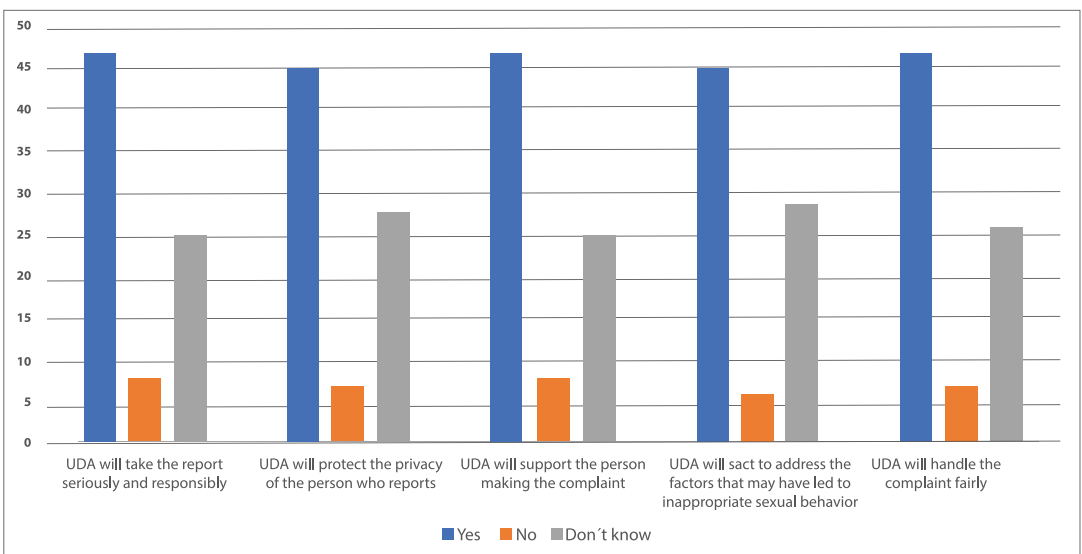


* The scale indicates the number of admnistratives who answered the survey. Source: Adapted from Gallup Inc. (2014)

Question 10 concerning knowledge about existing protocols yielded very diverse responses from the three groups with $75 \%$ of administration being familiar with them, $60 \%$ of teachers and $25 \%$ students.

Figure 4. Teachers, students and administrative survey, question 10: Do you know if the university has any regulations on violence on campus?

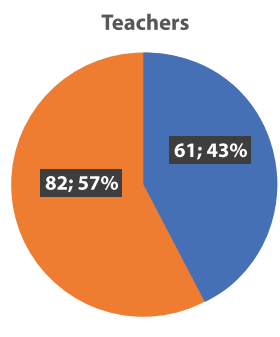

-Yes $\mathrm{no}$

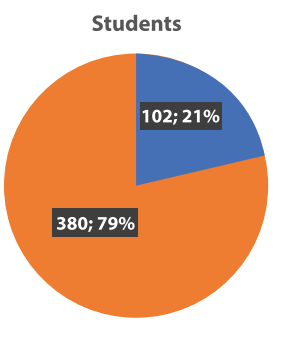

-Yes $=$ No

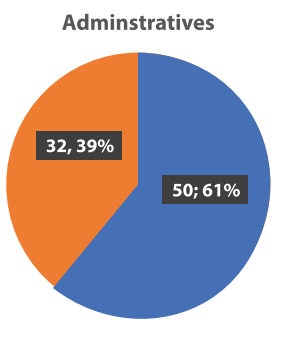

$\square$ Yes $₫$ No

* The scale indicates the number of people (teachers, students, administrators) who answered the survey. Source: Adapted from Gallup Inc. (2014)c. (2014)

Question 11 asked if there were other factors that, in the respondents' opinions, could improve campus security by rating the following protocols. There was, in fact, close agreement from the three respondent groups.

Figure 5. Question 11: Are there other factors that, in your opinion, could improve your campus security? Students should be removed from campus at he time of physically or verbally threatening another student.

The University should deny enrollment to those students whith bad behavior ( in relation to drug and alcohol consumption on campus)

Institutional staff have the responsability to report the behavior og aggressive students to the authorities

Students have the responsibility to report to the authorities the behavior of aggressive students
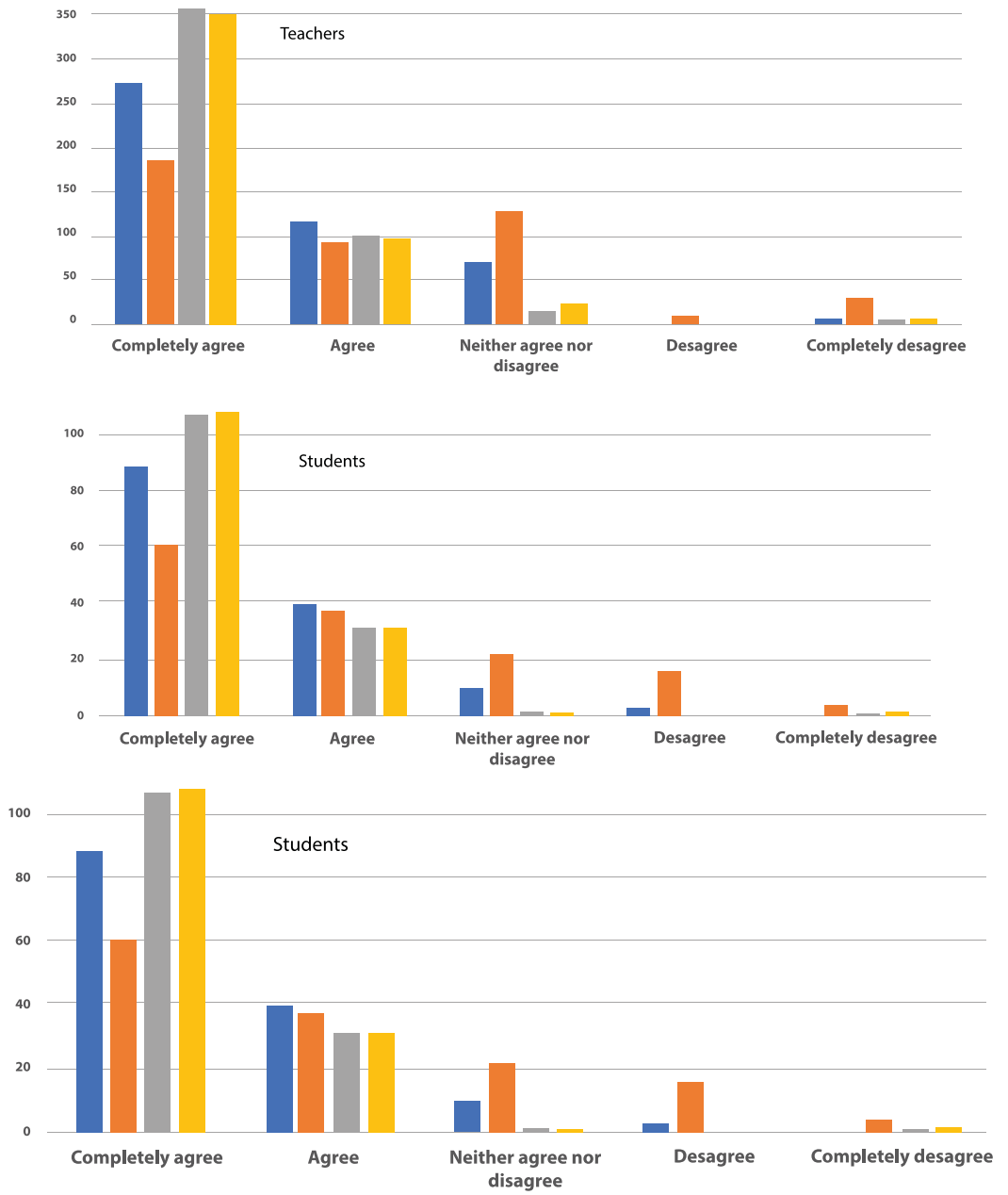
* The scale indicates the number of people (students, teachers, administrators) who answered the survey. Source: Adapted from Gallup Inc. (2014)

Question 12, "Other Comments," yielded many responses from each group. Example comments chosen were agreed by the authors of the research based on themes demonstrated in the intervention module: negotiation, equality, trust, accountability, personal growth, communication, role modelling and avoiding violence

Students comments:

1. I would love to have everyone protected in the university equally.... no "relatives" or "acquaintances" within the university. There is a clear feeling of bias for characters with certain types of surnames and "parents" .... or are "great entrepreneurs." Continue working for equality where the money is not a factor in determining certain causes. (equality, trust, accountability)

2. Focus on the behavior of teachers, not just students. (communication \& role modeling)

3. It is necessary that students can also report cases of teachers who attack students in any way and who drink alcohol inside the institution and encourage students to be aggressive. (accountability, role modeling, communication)

4. The university never takes or has taken action against sexual or physical harassment of students by students or, worse, teachers or representatives of the administration. (accountability, role modeling)

5. I think it is important to know what authority one can resort to in case of some type of abuse, and how is the system for people to access more easily. (accountability, communication, trust)

6. Many times, students do not report certain behaviors because they believe they are not "very serious." It should be made known that there is a complaint protocol and that it can be done in each case. (accountability, communication)

7. I think that this should be deepened a little more with teachers since some do give priority and facilities for the simple fact of gender; more attention should be paid to the behaviors of professors reported in the assessments than to the students. (accountability, role modeling, communication)

Teachers' comments (Question 12)

1. Very interesting, but I don't find any harassment of teachers to students, just as there is nothing about authorities' harassment to teachers and students. Not only at the sexual level, but at the level of discrimination based on political ideas, ethnic self-definition, generic gender identity, and religious beliefs. The UDA is a highly intolerant space regarding the diversity of opinions, which supports some, and represses others. And that comes directly from the administrative implementation of the policy. It seems to me that denying enrollment to those students with bad behavior is very drastic. (accountability, communication, trust)

2. I think that there must be an accompaniment to the students, and above all, it must work in prevention and foster an environment of respect. (accountability, trust, negotiation)

3. I think that violence often finds its origin in language; it would be essential to promote a strong campaign of good use of language, tangibly conditioning those who express themselves with vulgar language within the university fields. (accountability)

4. The University must improve its communication strategies regarding sexual assault or harassment since many students (and teachers) are unaware of the institution's policies and process to investigate them. As this is not known, students do not know where to go or what will happen if they make a complaint and have the right to know. (accountability)

5. Promote educational spaces that rescue moral and ethical values. (trust, equality, negotiation)

6. It is important that the University addresses serious training processes to understand the root problems of coexistence and violence. Within the area of anthropology, we have contents that point to the study of how the processes of racism, machismo, homophobia among others, are a proposal of academic analysis, but also of collective analysis about our behaviors and how socially we can give change responses to eradicate all forms of discrimination that reproduce unfair societies. I applaud this initiative, and it would be convenient to start dialogues with teachers that we are working on these issues from our areas of knowledge. (accountability, communication)

\section{Administration comments (Question 12)}

1. Internal communication should be improved, on provisions, regulations, to improve administrative staff's actions. 
(communication, accountability)

2. A socialization is necessary for everything related to the subject. Thank you. (trust, equality, communication)

3. The fear of denouncing certain acts of violence is always present; that is why the awareness of the people that denounce these acts is to assert the rights of the people, and even a life that is in danger would be saved. The silence of this type of act makes us complicit. (accountability)

4. In question 11, the perspective of the people can vary a lot because there are cases and cases and the situation of each student should be taken into account; in addition, there is much talk about the behaviors of the students, but nothing is mentioned about the teachers and the administrative staff of the University also form part of the community. At any given time, we could all be victims and be victimizers. (accountability, trust, role modeling)

5. The Security Commission should meet regularly. (accountability)

6. Office staff are not safe inside after 5.00 when there is minimal security outside and none inside. (accountability)

Student comments from the convenience intervention focus group:

I want my parents to see this content.

1. This is a feminist focus on only women's rights.

2. Teachers need to learn how to teach. We have everything online. They should be more like sports referees.

3. Teachers need to learn how to negotiate everything, especially control.

4. We don't know what the university will do if we report violence.

5. There should be more counseling.

6. I want to know how to help my friend.

\section{Photo images}

Twenty-seven photos with text submissions were received. A panel of four judges from different schools in the University reviewed and collectively chose the most representative of student experiences of friendship, mobility, solidarity, and respect for each other. Each photo submission was accompanied by a text of not more than 280 characters defining or adding to what could be seen in the photo, what was happening, should the situation be discussed and what could be done about it. Here is part of the text that accompanied the winning photo:

... by having a prosocial attitude, which seeks to foster empathy for people who are going through difficult situations and that their mood often does not allow them to seek help. It is a problem that occurs daily in the University community that often goes unnoticed; Therefore, we must promote the importance of mental health since, as well as physical health, its imbalance has consequences in different areas of a person's life. It is a problem that occurs daily in the university community, and that often goes unnoticed.

Figure 6. Winning photo of the Student Photo Competition 2019, University of Azuay.

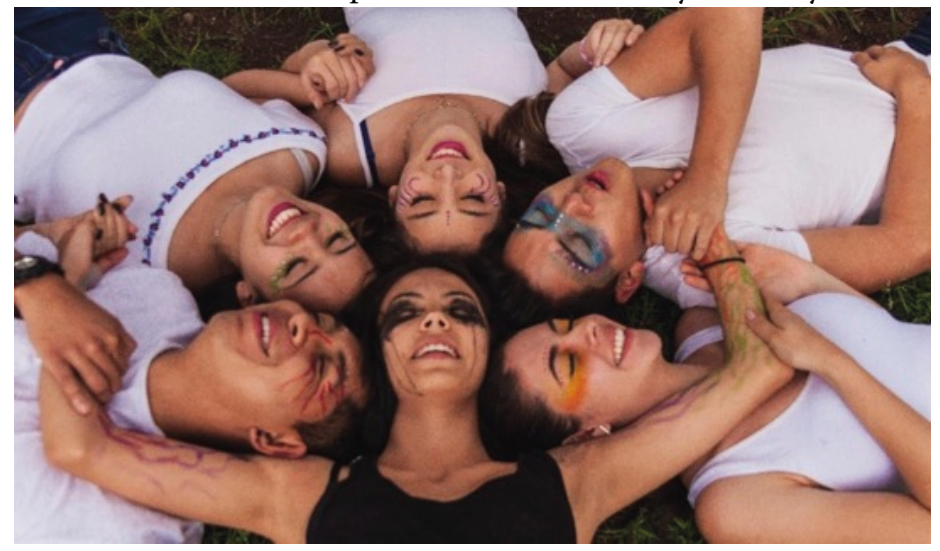

\section{Discussion}

Whereas that there are descriptive statistical differences in the Survey amongst the three participating groups - students, 
teachers, and administration - from both quantitative Survey as well as textual and photographic images - the theme of accountability prevails especially related to existing and future policy about the wellbeing of all campus community members.

While this paper will use the English word "accountability," a clearer meaning in Spanish is either 'cuentas claras' (clear accounting) or 'transparencia' (transparency). Accountability refers to the exercise of power, but its directionality remains profoundly ambiguous. Who is supposed to be accountable to whom, and who decides?

In the context of campus wellbeing and accountability, upward accountability involves students reporting (whether it is attendance, responsibility for assignments, peer relationships or victimization to their teachers, who in turn report to administrators/policymakers, who may report to national funders and donors. In contrast, downward accountability refers to policymakers being responsible to their national (government) and local public. This raises the question: if the arrow is supposed to go both ways, what happens when these pressures push in opposite directions?

This question of the directionality of accountability relationships is especially relevant in the field of campus wellbeing where an upward notion of accountability often predominates because of its association with institutional compliance in terms of governmental requirements, financial inputs, and output metrics. This approach pulls accountability upwards and inwards, towards funders and donors, rather than downwards and outwards, towards teachers and particularly students. For example, while funder reporting requirements for educational institutions have led to the creation of elaborate monitoring systems, the resulting institutional performance data may rarely be proactively disclosed to the teachers and students. There is a major missed opportunity if the data are not made available to enable action to help identify and address impediments. Governmental and donor-driven agendas may not measure the actual day-to-day quality of wellbeing in particular but rather required legal obligations. For example, having a significant policy for denouncing violence needs to be effectively communicated to more than administration but also in ways that teachers and especially students are aware of so that it can be practiced by all members of the institution together as a significant aspect of wellbeing.

\section{Recommendations}

The main objectives of the study were:

- To collect policy-relevant data on the extent and distribution of various types of victimization that students may have experienced through self-report

- To focus on the perceptions of students, teachers, and administration on the campus' social and cultural climate

- Their knowledge of types of support services that are provided

- Their perceptions of how UDA would handle a situation in which a student reported an incident of gender-based violence/ misconduct.

From the quantitative and qualitative findings related to the accountability of campus wellbeing based on the Higher Education Law requirements in Ecuador, the following general recommendations for how a university can work with all community members are discussed and then set out as a timetable of objectives.

To increase broad campus-community engagement and accountability is necessary, collaboration and communication are central to a comprehensive campus model and represent the primary mechanism by which innovation about wellbeing is spread. The development of a coordinated campus team (administration, teachers, support staff, and students) to guide institutional change and ensure comprehensive programming could effectively address campus wellbeing to:

1. develop and implement effective policies and protocols about the wellbeing of everyone on campus;

2. conduct on-going campus-wide assessments, strengths and gap analyses, and evaluation of its efforts so that programs can adapt to the changing needs of its community;

3. ensure leadership across the campus is engaged, knowledgeable about, and supports a survivor-centered approach with a clear understanding of student demographics on campus; 
4. ensure that all campus community levels receive ongoing training in awareness and prevention of various types of victimization, for example, sexual assault, dating violence, stalking and any other forms of intimidation to minorities, as well as drug and alcohol issues.

\section{Effective intervention strategies}

In addition to community engagement, there needs to be a focus on creating effective interventions in a meaningful sequence. Effective interventions move the campus toward fair and consistent offender accountability and include comprehensive policies that strengthen campus security and investigative strategies. They also support appropriate disciplinary actions that hold offenders accountable and

1. provide survivor-centered victim services and advocacy;

2. clarify other individual or group support services, e.g., counseling (MIUDA)

3. ensure a trauma-informed and effective legal response if appropriate

4. create and maintain fair, equitable internal disciplinary processes that hold offenders accountable.

A comprehensive campus model of wellbeing includes prevention and education programming that reflects a multitiered approach, including primary prevention strategies in addition to education and awareness efforts.

Although the pilot education module about generic intervention reflected students' broader perceptions of both inside and outside the campus (family and societal relations), research indicates that effective prevention efforts involve more than one-time programming and awareness events (need reference here). Prevention consists of multiple methods of dissemination (printed, social media, focus groups) to incoming students receiving information about campus policies and resources related to:

- prevention strategies that are comprehensive and campus culturally relevant;

- multiple easily accessible prevention education based on self-help strategies as well as bystander intervention strategies

- ongoing education prevention training for faculty and staff; and communication of campus norms that state what is not tolerated and that everyone has a role to play in prevention and intervention especially given the noted lack of student knowledge concerning University protocols for reporting violent incidents and outcomes.

To enact responsive planning for change with all members of the university community, a 'Wellbeing Working Group' led by a student health coordinator with resources for both individual and group counseling and ability access, support for teacher learning, a security team coordinator and student representatives is required to being the process. A plan should consist of five action areas.

Table 7. Action area 1: Foster engaging curricula and learning experiences that build competence, foster intrinsic motivation, and create social connections.

\begin{tabular}{|l|c|}
\hline \multicolumn{1}{|c|}{ ACTION } & $\begin{array}{c}\text { RESPONSIBILITY } \\
\text { Support for Teacher Learning } \\
\text { Coordinator }\end{array}$ \\
$\begin{array}{l}1.1 \text { Embed resources into the curriculum of each School to } \\
\text { support the students' wellbeing and learning experiences. }\end{array}$ & $\begin{array}{c}\text { Learning Support } \\
\text { Counselling \& Access Services, } \\
\text { Learn }\end{array}$ \\
\hline $\begin{array}{l}1.2 \text { Implement a Wellbeing Liaison program for each School to } \\
\text { improve awareness of services and collaboration. }\end{array}$ & $\begin{array}{c}\text { Learning Support \& Student } \\
\text { Health Coordinator. }\end{array}$ \\
\hline $\begin{array}{l}1.3 \text { Promote teaching and learning resources that support } \\
\text { student health and wellbeing. }\end{array}$ & Learning Support. \\
\hline $\begin{array}{l}1.4 \text { Maintain a MiUDA page and/or collaboration site as a } \\
\text { repository for resources/links. }\end{array}$ & Student Health Coordinator. \\
\hline $\begin{array}{l}1.5 \text { Engage in research on teaching practices that support } \\
\text { student wellbeing. }\end{array}$ & Support for Learning. \\
\hline
\end{tabular}

Table 8. Action area 2: Support the health and wellbeing of students by creating and maintaining healthy organizational, learning, 
cultural, social, and natural environments.

\begin{tabular}{|l|c|}
\hline \multicolumn{1}{|c|}{ ACTION } & RESPONSIBILITY \\
\hline $\begin{array}{l}\text { 2.1 Update and expand online health and wellbeing resources, and } \\
\text { ensure content is accessible for all students. }\end{array}$ & Student Health Coordinator \\
\hline 2.2 Promote the safety of students on campuses. & Security Community Team \\
\hline 2.3 Training for staff to support student mental health and wellbeing. & Counseling Services. \\
\hline 2.4 Training and support for Wellbeing Peer Leader activities. & Student Health Coordinator. \\
\hline 2.5 Student mental health and wellbeing needs analysis. & Student Health Coordinator. \\
\hline $\begin{array}{l}\text { 2.6 Develop a toolkit to help staff to support students with mental } \\
\text { health conditions. }\end{array}$ & $\begin{array}{c}\text { Manager, Counselling } \\
\text { Services. }\end{array}$ \\
\hline
\end{tabular}

Table 9. Action area 3: Provide students with information, resources, and skills needed to take greater control of their overall health and wellbeing.

\begin{tabular}{|l|c|}
\hline \multicolumn{1}{|c|}{ ACTION } & RESPONSIBILITY \\
\hline $\begin{array}{l}\text { 3.1 Promote Student Wellbeing services on campus throughout } \\
\text { the semester }\end{array}$ & Counselling \& Access Services \\
\hline $\begin{array}{l}\text { 3.2 Promote online health and wellbeing resources on student } \\
\text { communication channels }\end{array}$ & Student Health Coordinator \\
\hline $\begin{array}{l}\text { 3.3 Broaden the online resources offered across a range of mental } \\
\text { health and wellbeing issues }\end{array}$ & Student Health Coordinator \\
\hline $\begin{array}{l}\text { 3.4 Support student-led projects and mental health and wellbeing } \\
\text { resource development }\end{array}$ & Student Health Coordinator \\
\hline $\begin{array}{l}\text { 3.5 Student Committee to represent the student voice in } \\
\text { consideration of student health issues }\end{array}$ & $\begin{array}{c}\text { Student Committee } \\
\text { Student Committee }\end{array}$ \\
\hline $\begin{array}{l}\text { 3.6 Regular mental health promotion awareness-raising } \\
\text { campaigns }\end{array}$ & $\begin{array}{c}\text { Student Health Coordinator } \\
\text { Human Resources }\end{array}$ \\
\hline
\end{tabular}

Table 10. Action area 4: Develop and create opportunities to build in particular mental health knowledge and skills, so students are engaged and thriving in both their academic and personal pursuits.

\begin{tabular}{|l|c|}
\hline \multicolumn{1}{|c|}{ ACTION } & \multicolumn{1}{|c|}{ RESPONSIBILITY } \\
\hline $\begin{array}{l}\text { 4.1 Face to face training: wellbeing drop-ins, mental health } \\
\text { awareness. }\end{array}$ & $\begin{array}{c}\text { Counseling Services \& } \\
\text { Student Health Coordinator. }\end{array}$ \\
\hline $\begin{array}{l}\text { 4.2 Online modules: Mental Health First Aid (alcohol and drug } \\
\text { intervention). }\end{array}$ & $\begin{array}{c}\text { Counseling Services \& } \\
\text { Student Health Coordinator. }\end{array}$ \\
\hline $\begin{array}{l}\text { 4.3 Peer-led skills development: mental health and wellbeing } \\
\text { training for student leaders and student groups. }\end{array}$ & Counseling Services. \\
\hline $\begin{array}{l}\text { 4.4 Students: mental health and wellbeing embedded into training; } \\
\text { increased opportunities for social connection. }\end{array}$ & $\begin{array}{c}\text { Counseling Services \& Student } \\
\text { Health Coordinator. }\end{array}$ \\
\hline $\begin{array}{l}\text { 4.5 Investigate opportunities to incorporate topics related to } \\
\text { mental health, mental illness or mental health organizations into } \\
\text { assessment items. }\end{array}$ & \begin{tabular}{l} 
Student Health Coordinator. \\
\hline
\end{tabular}
\end{tabular}

Table 11. Action area 4: Develop and create opportunities to build in particular mental health knowledge and skills, so students are engaged and thriving in both their academic and personal pursuits. Action area 5: Create and maintain services that enhance mental health and wellbeing and support equitable access across campus

\begin{tabular}{|c|c|}
\hline ACTION & RESPONSIBILITY \\
\hline 5.1 Promoting and ensuring access to student support services. & $\begin{array}{c}\text { Support for Learning } \\
\text { Counseling \& Access Service. }\end{array}$ \\
\hline 5.2 Providing individual and group support. & $\begin{array}{c}\text { Counseling \& Access } \\
\text { Services. }\end{array}$ \\
\hline $\begin{array}{l}5.3 \text { Conduct wellbeing forums/focus groups to inform data-driven } \\
\text { service delivery that addresses the identified needs of students. }\end{array}$ & Access \& Ability Services. \\
\hline 5.4 Increasing engagement with external mental health resources & $\begin{array}{c}\text { Counseling Services } \\
\text { AccessAbility Services. }\end{array}$ \\
\hline
\end{tabular}


Each institution can implement the recommended process according to its strategic plan. Follow-up surveys allow all campus community members to give feedback (Student Wellbeing 2020 Survey, Columbia University follow up to 2018 campus survey).

\section{Referencias}

1. Altbach, P. G. (2004). Globalisation and the university: Myths and realities in an unequal world. Tertiary Education \& Management, 10(1), 3-25.

2. Call to Men (2020). LIVE Respect on Campus Toolkit. VAWnet.org. Accessed June 1. https://vawnet.org/material/ live-respect-campus-toolkit.

3. Baik, C., Larcombe, W., Brooker, A., Wyn, J., Allen, L., Brett, M., James, R. (2016). A Framework for Promoting Student Mental Wellbeing in Universities. Melbourne: University of Melbourne.

4. Brackmann, M. M. (2010). Internacionalização da educação superior e política externa brasileira: estudo da criação da Universidade Federal da Integração Latino-Americana (UNILA).

5. Columbia University (2020). Student Well-Being Survey. Columbia University Life. https://universitylife.columbia. edu/wellbeingsurvey.

6. Consejo de Educación Superior. (2010, October 12). Ley Orgánica de Educación Superior, LOES, Registro Oficial No. 298.

7. Charter, O. (2015). An international charter for health promoting universities and colleges. Kelowna: sn.

8. Gallup Inc. (2014). Great jobs, great lives. Washington DC: Gallup, Inc.

9. Haraway, D. (1988). Situated knowledges: The science question in feminism and the privilege of partial perspective. Feminist studies, 14(3), 575-599.

10. Harper, D. (1986). Meaning and work: A study in photo elicitation. Current sociology, 34(3), 24-46.

11. Holt, M., \& Powell, S. (2017). Healthy Universities: a guiding framework for universities to examine the distinctive health needs of its own student population. Perspectives in public health, 137(1), 53-58.

12. Ibáñez, D. B. (2017). La violencia de género en Ecuador: un estudio sobre los universitarios. Revista Estudios Feministas, 25(3), 1313-1327.

13. Knight, J. (2004). Internationalization remodeled: Definition, approaches, and rationales. Journal of studies in international education, 8(1), 5-31.

14. Liebenberg, L. (2009). The visual image as discussion point: Increasing validity in boundary crossing research. Qualitative research, 9(4), 441-467.

15. Liebenberg, L., Ungar, M., \& Theron, L. (2014). Using video observation and photo elicitation interviews to understand obscured processes in the lives of youth resilience. Childhood, 21(4), 532-547.

16. Mitchell, C. (2015). Looking at showing: On the politics and pedagogy of exhibiting in community-based research and work with policy makers. Educational Research for Social Change, 4(2), 48.

17. Orygen. (2017). Under the Radar: The Mental Health of Australian University Students. Orygen. The National Centre of Excellence in Youth Mental Health. 
18. Puig de la Bellacasa, M. 2017. Matters of care: Speculative ethics in more than humanworlds. Minneapolis: University of Minnesota Press.

19. Smith, D. E. (1987). The everyday world as problematic: A feminist sociology. University of Toronto Press.

20. Stein, S., Andreotti, V., Bruce, J., \& Suša, R. (2016). Towards different conversations about the internationalization of higher education. Comparative and International Education, 45(1), 2.

21. University of California. Request for Proposals for Global Grants for University Campus-Based Violence Prevention Research. Global Health Institute. https://ucghi.universityofcalifornia.edu/centers-of-expertise/womens-healthgender-and-empowerment/request-proposals.

22. Wang, C., \& Burris, M. A. (1994). Empowerment through photo novella: Portraits of participation. Health education quarterly, 21(2), 171-186. 